\title{
The Predictive Value of Cervical Length During the Second Trimester for Non-Medically Induced Preterm Birth
}

\author{
Ying Wang \\ Jie Ding \\ Hong-Mei Xu
}

Department of Obstetrics and Gynecology, Beijing Fengtai Hospital, Beijing, I0007I, People's Republic of China
Correspondence: Hong-Mei Xu Department of Obstetrics and Gynecology, Beijing Fengtai Hospital, No. 99 of Fengtai South Road Street, Fengtai District, Beijing, I0007I, People's Republic of China

Tel +86 I86I l083322

Emailxhm_drxu@I63.com
Objective: The aim of the present study was to investigate the predictive value of transvaginal ultrasonography measurement of cervical length (CL) during the second trimester for spontaneous preterm birth.

Methods: Data from 1222 women with a single fetus pregnancy, who delivered at our hospital between March 2019 and May 2020, were retrospectively analyzed. CL was measured during the second trimester, with a length of $<25 \mathrm{~mm}$ regarded as cervical shortening. The relationship between CL, cervical shortening, and pregnancy outcome was analyzed.

Results: The incidence of spontaneous preterm birth and cervical shortening in the 1222 women was $7.3 \%(89 / 1222)$ and $0.33 \%$ (4/1222), respectively. The average CL during the second trimester was $37.9 \pm 5.7 \mathrm{~mm}$ for the spontaneous preterm birth group and 39.3 $\pm 3.8 \mathrm{~mm}$ for those who gave birth at full term. Three of the four cases of cervical shortening resulted in a spontaneous preterm birth. This showed a predictive sensitivity of $3.33 \%$ and a specificity of $99.9 \%$.

Conclusion: CL measurement during the second trimester can be used as a routine test to predict spontaneous preterm birth. During the second trimester, the distribution of CL in women with single fetus pregnancies in China is different compared with other countries. Reducing the threshold of CL may improve the predictive value for preterm birth.

Keywords: second trimester, cervical length, cervical shortening, premature birth prediction, spontaneous preterm birth

\section{Introduction}

Preterm birth is defined as the termination of pregnancy between 28 and 37 weeks of gestation. It is a significant cause of perinatal morbidity and mortality. Preterm births can be divided into two categories: spontaneous and therapeutic. Spontaneous preterm labor includes spontaneous preterm birth (SPB) and preterm premature rupture of membranes (PPROM), while therapeutic preterm birth is defined as pregnancy complications or comorbidities that require termination before 37 weeks of gestation. SPB is the focus of strategies to reduce preterm birth rates and perinatal morbidity and mortality. In recent years, due to advances in the care of preterm and low-birthweight infants, survival rates have significantly improved, and disability rates have decreased. However, a survey conducted jointly by four hospitals in Beijing on the current incidence and outcome of preterm births in the city showed that despite medical advances, the mortality rate of preterm infants is 
still high. This is especially true for those born at less than 32 weeks of gestation, where the rate is $22.1 \%$. ${ }^{1}$ Between 1990 and 2010, the global preterm birth rate increased to $11.1 \%$. Although China does not rank in the top 10 countries worldwide for preterm birth rates, the actual number of preterm births is the second highest in the world due to the large population. ${ }^{2}$ Thus, it is crucial to reduce the incidence of preterm birth in China.

Currently, there is no effective method to extend gestation for preterm births that are already in labor. Once preterm labor is clinically diagnosed, uterine contraction inhibitors cannot prevent the delivery. However, studies of pregnant women presenting with symptoms of preterm labor have shown that only about $10 \%$ will deliver within seven days, and about $75 \%$ will deliver at full term. ${ }^{3}$ Thus, therapeutic interventions that appear to improve prognoses, such as hospitalization for observation, transfer to the hospital, and glucocorticoid application, may not be necessary. Therefore, improvements in the sensitivity and specificity of prediction methods for preterm birth have been the focus of recent research. Cervical length (CL) during the second trimester is closely correlated with the risk of preterm birth, and the shorter the CL, the higher the risk of preterm birth. ${ }^{4,5}$ Based on these findings, CL during the second trimester and pregnancy outcome in 1222 women with single fetus pregnancies were investigated in the present study to explore the predictive value of CL measurement during the second trimester for spontaneous preterm birth in China.

\section{Materials and Methods Source of Material}

Between March 2019 and May 2020, 1361 women with single fetus pregnancies delivered at the Department of Obstetrics and Gynecology of our hospital. After excluding 92 women transferred from other hospitals, 36 women who did not undergo CL measurement during the second trimester, and 11 who failed to follow-up with the pregnancy outcome, 1222 women were enrolled. All participants underwent $\mathrm{CL}$ measurement during the second trimester. The average age of the women was $30.6 \pm 3.1$ years old. The average number of pregnancies was $1.8 \pm$ 0.8 , and the average number of births was $1.1 \pm 0.2$.

This study was performed in accordance with the principles stated in the Declaration of Helsinki and approved by the Ethics Committee of Beijing Fengtai Hospital. All participants provided the written informed consent.

\section{Inclusion and Exclusion Criteria}

Inclusion criteria: all women with a single fetus pregnancy who underwent routine ultrasonography screening for deformity and health care at our hospital between 20 and 24 weeks of gestation.

Exclusion criteria: women with a single fetus pregnancy who did not undergo routine ultrasonography screening for deformity at our hospital between 20 and 24 weeks of gestation, pregnancies involving multiple fetuses, women in whom labor was induced due to maternal and fetal factors before 37 weeks of gestation, and women who failed to follow-up before 37 weeks of gestation.

\section{Detection Methods of CL}

CL was measured by transvaginal ultrasonography during the second trimester (22-24 weeks of gestation) with an ultrasonography instrument provided by GE Ultrasound E8, USA. The women were asked to empty their bladders before the examination. The probe was placed in the anterior vaginal fornix, and the cervix was gently touched without excessive force. After gently rotating to the sagittal section of the cervix, the image was magnified to more than $75 \%$ of the full screen. When the endocervix, ectocervix, all of the cervical canal, and the anterior amniotic sac were clearly displayed, the distance from the endocervix to the ectocervix was measured as the CL. Measurement only took place in the absence of uterine contractions. The process was repeated three times, and the smallest value was used. ${ }^{6,7}$

\section{Classification Criteria for Preterm Birth}

Due to their differing etiologies, preterm births can be classified as either spontaneous or therapeutic. The former category includes SPB and PPROM, while the latter includes pregnancies terminated early for the safety of the mother and child due to comorbidities or complications. ${ }^{6}$

\section{Diagnostic Criteria for Cervical Shortening}

In the present study, a CL of $<25 \mathrm{~mm}$ was defined as cervical shortening. ${ }^{6}$

\section{Statistical Methods}

SPSS 13.0 software was used for data analysis. The data were expressed as mean \pm standard difference. The $\chi^{2}$ test 
was used to compare rates. A p-value of $<0.05$ was considered to be statistically significant.

\section{Results}

\section{Incidence and Distribution of Preterm}

\section{Birth and Cervical Shortening} Incidence and Distribution of Preterm Birth

Preterm birth occurred in 131 (10.7\%) of the 1222 women, while 1091 women gave birth at full term. Overall, there were $89(7.3 \%)$ cases of spontaneous preterm birth (20 cases with SPB and 69 cases with PPROM) and 42 (3.4\%) cases of therapeutic preterm birth.

\section{Incidence and Distribution of Cervical Shortening} Cervical shortening occurred in four $(0.33 \%)$ of the 1222 women. Of these, three women went on to have a spontaneous preterm birth (two cases of SPB and one case of PPROM). The remaining woman gave birth at full term. No cases of therapeutic preterm birth were observed (Figure 1)

\section{Cervical Length During the Second Trimester and Gestational Age at Birth}

The average CL in women who had a spontaneous preterm birth was $37.9 \pm 5.7 \mathrm{~mm}$. These measurements were $36.7 \pm$ $8.2 \mathrm{~mm}$ and $38.2 \pm 4.8 \mathrm{~mm}$ in the SPB and PPROM groups, respectively. The average $\mathrm{CL}$ in the full-term birth group was $39.3 \pm 3.8 \mathrm{~mm}$.

Second-trimester CL was shortest in the SPB group and longest in the full-term birth group, but the differences were not statistically significant between the three groups, as shown in Table 1 .

\section{Cervical Shortening as a Predictor of Spontaneous Preterm Birth}

Overall, there were four cases of cervical shortening. Three (3.4\%) of these occurred in the 89 women who had a spontaneous preterm birth. The remaining case $(0.09 \%)$ occurred in the 1091 women who had a full-term birth. The incidence of cervical shortening was significantly different between these two groups $(\mathrm{p}<0.001)$, as shown in Table 2 .

\section{Discussion}

After the second trimester of pregnancy, as the amniotic fluid increases and the fetus grows, the pressure inside the uterine cavity gradually increases. The fetal sac may protrude from the endocervix, causing the cervical canal to shorten and dilate. Once the cervix has dilated past a certain point, it will cause contractions or rupture of the membranes and preterm birth. Preterm birth, which has an incidence of $5-12 \%$, is a chief cause of perinatal morbidity and mortality and, thus, the research focus. ${ }^{8}$ Studies in China have reported that the incidence of preterm birth varies greatly, from $5.4 \%{ }^{9}$ to $13.1 \%{ }^{1}$ In the present study, the overall incidence of preterm birth was $10.7 \%$, and that of spontaneous preterm birth, $7.3 \%$. These results are similar to those in other studies. ${ }^{1,8-10}$

There is a focus on the prevention of preterm birth. If a delivery that is about to occur can be identified early, clinical intervention and treatment to prevent contractions

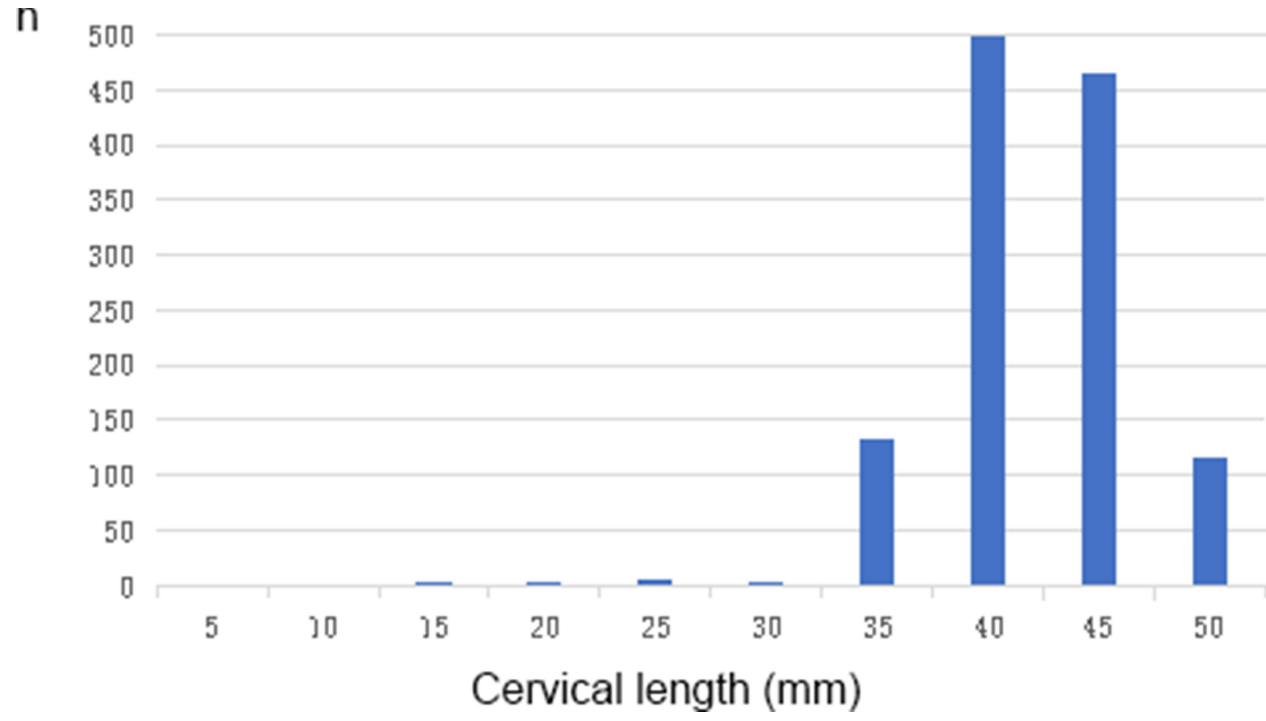

Figure I Distribution of cervical length in the second trimester. 
Table I Descriptive Data Concerning the Cervical Length with Different Gestational Age at Birth

\begin{tabular}{|l|c|c|c|}
\hline Group & $\mathbf{n}$ & Mean (Standard Deviation) & Range (Minimum-Maximum) \\
\hline SPB group & 20 & $36.7(8.2)$ & $14.0-47.1$ \\
PPROM group & 69 & $38.2(4.8)$ & $23.0-46.5$ \\
Full-term birth group & 1091 & $39.3(3.8)$ & $23.0-48.0$ \\
$X^{2}$ & & 0.38 & \\
P & & $>0.05$ & \\
\hline
\end{tabular}

Abbreviations: SPB, spontaneous preterm birth; PPROM, preterm premature rupture of membranes.

Table 2 Prediction of Spontaneous Preterm Birth by Cervical Shortening

\begin{tabular}{|l|c|c|}
\hline $\begin{array}{l}\text { Cervical Length } \\
(\mathbf{m m})\end{array}$ & $\begin{array}{c}\text { Spontaneous Preterm } \\
\text { Labor }\end{array}$ & $\begin{array}{c}\text { Full-Term } \\
\text { Birth }\end{array}$ \\
\hline$<25$ & 3 & $\mathrm{I}$ \\
$\geq 25$ & 86 & 1090 \\
$\mathrm{X}^{2}$ & 26.19 & \\
$\mathrm{P}$ & $<0.001$ & \\
\hline
\end{tabular}

and further dilation of the cervical canal may reduce the occurrence of preterm delivery. Several studies have shown that cervical shortening is closely correlated with the occurrence of preterm birth, ${ }^{4,5}$ and clinical guidelines also recommend that CL measurement be used in the prediction of preterm birth. ${ }^{6,11}$ Despite this, primary hospitals have not yet widely implemented routine CL measurement during the second trimester. While early studies showed that the second-trimester CL measurement had no significant predictive value for preterm birth in asymptomatic women, ${ }^{12}$ recent guidelines recommend that the transvaginal ultrasonography measurement of CL during the second trimester be used to predict preterm birth, ${ }^{11}$ and some studies recommend it as a routine screening item. ${ }^{4,13}$ Chinese guidelines recommend CL measurement as one method for predicting preterm birth but do not recommend routine screening in low-risk populations. ${ }^{6}$ However, studies have shown that routine CL screening during the second trimester can predict and reduce the occurrence of threatened preterm labor and preterm birth. ${ }^{14}$ In the present study, CL measurement was performed at the same time as ultrasonography screening for deformity, which did not add an extra financial burden. The procedure predicted the occurrence of preterm birth with a specificity of $99.9 \%$, and it is recommended as a routine screening program that could be promoted in primary hospitals. Once cervical shortening is detected, prompt intervention could help reduce the incidence of preterm birth.
CL has a low sensitivity of $3.37 \%$ in this study for predicting preterm birth. ${ }^{9}$ This might be due to a correlation with other factors that affect the initiation of the birth mechanism, such as infection. ${ }^{15}$ The present study showed that the incidence of PPROM was much higher than the incidence of SPB. Furthermore, gestational age at birth was significantly lower in the PPROM group than in the SPB group, and there was also a higher incidence of adverse pregnancy outcomes (five emergency cesarean deliveries due to fetal distress and three cases with intrauterine infections) than in the SPB group (one case of fetal distress). Therefore, improving the incidence of infection during pregnancy may reduce the incidence of preterm birth and improve maternal and fetal outcomes.

In the present study, the incidence of cervical shortening was similar to that seen in another Chinese study ${ }^{9}$ and much lower than those reported in other countries. ${ }^{10,16}$ A similar pattern was seen for average CL, both overall ${ }^{9,16}$ and in women who had a full-term birth. ${ }^{16,17}$ Thus, the distribution of CL in Chinese women appears to be different from other countries.

Some studies have suggested that a CL of $25 \mathrm{~mm}$ is a suitable predictive threshold for women with a previous history of preterm birth, while $20 \mathrm{~mm}$ is more appropriate in pregnancies without high-risk factors present. ${ }^{5}$ The current study revealed that spontaneous preterm birth occurred in $75.0 \%$ of the pregnant women with a $\mathrm{CL}<25 \mathrm{~mm}$ and in all of those with a CL $<20 \mathrm{~mm}$, which is significantly higher than the $34.1 \%$ reported elsewhere. ${ }^{18}$ Whether the predictive value of CL would increase if the threshold were reduced requires further extensive studies.

The limitations in the present study include a small sample size, giving rise to uncertainty in the study results. A multicenter study based on a large sample would provide more accurate results and a better basis for clinical practice. 


\section{Conclusion}

The present study suggests that second-trimester CL measurement could be used as a routine test to predict spontaneous preterm birth. As the distribution of CL in China appears to be different from other countries, the threshold of CL should be reduced to improve its value in predicting preterm births.

\section{Funding}

2018 Fengtai District Health System Scientific Research Project (2018-36).

\section{Disclosure}

The authors declare that they have no competing interests.

\section{References}

1. Guo ZK, Ma JM, Gan L, et al. [Preterm birth and preterm infants in Beijing regional district]. Chin J Obstet Gynecol. 2010;45:99-103. (Chinese).

2. Blencowe H, Cousens S, Chou D, et al.; Born Too Soon Preterm Birth Action Group. Born too soon: the global epidemiology of 15 million preterm births. Reprod Health. 2013;10(Suppl 1):S2. doi:10.1186/ 1742-4755-10-S1-S2

3. Ness A, Visintine J, Ricci E, Berghella V. Does knowledge of cervical length and fetal fibronectin affect management of women with threatened preterm labor? A randomized trial. Am J Obstet Gynecol. 2007;197:426.e1-7. doi:10.1016/j.ajog.2007.07.017

4. Slager J, Lynne S. Assessment of cervical length and the relationship between short cervix and preterm birth. J Midwifery Womens Health. 2012;57(Suppl 1):S4-11. doi:10.1111/j.1542-2011.2012.00209.x

5. Vink J, Feltovich H. Cervical etiology of spontaneous preterm birth. Semin Fetal Neonatal Med. 2016;21:106-112. doi:10.1016/j. siny.2015.12.009

6. Hu YL. [Guidelines for clinical diagnosis and treatment of premature birth (2014)]. Chin J Obstet Gynecol. 2014;49:481-485. (Chinese).

7. Kagan KO, Sonek J. How to measure cervical length. Ultrasound Obstet Gynecol. 2015;45:358-362. doi:10.1002/uog.14742

8. Goldenberg RL, Culhane JF, Iams JD, Romero R. Epidemiology and causes of preterm birth. Lancet. 2008;371:75-84. doi:10.1016/S01406736(08)60074-4
9. Qu SH, Shi CY, Chen Q, et al. [Predictive value of cervical length by transvaginal sonography for preterm pregnancy during mid-and late-trimester of pregnancy]. Chin $J$ Obstet Gynecol. 2011;46:748-752. (Chinese).

10. Celik E, To M, Gajewska K, Smith GC, Nicolaides KH; Fetal Medicine Foundation Second Trimester Screening Group. Cervical length and obstetric history predict spontaneous preterm birth: development and validation of a model to provide individualized risk assessment. Ultrasound Obstet Gynecol. 2008;31:549-554. doi:10.1002/uog. 5333

11. Berger R, Abele H, Bahlmann F, et al. Prevention and Therapy of Preterm Birth. Guideline of the DGGG, OEGGG and SGGG (S2k Level, AWMF Registry Number 015/025, February 2019) - Part 1 with recommendations on the epidemiology, etiology, prediction, primary and secondary prevention of preterm birth. Geburtshilfe Frauenheilkd. 2019;79:800-812. doi:10.1055/a-0903-2671

12. Dilek TU, Yazici G, Gurbuz A, et al. Progressive cervical length changes versus single cervical length measurement by transvaginal ultrasound for prediction of preterm delivery. Gynecol Obstet Invest. 2007;64:175-179. doi:10.1159/000106486

13. Larma JD, Iams JD. Is sonographic assessment of the cervix necessary and helpful? Clin Obstet Gynecol. 2012;55:324-335. doi:10.1097/GRF.0b013e3182487e96

14. Zhi MC, Zhao XY, Li ZA, Li W. [Study on the correlation between premature labor and universal screening transvaginal ultrasound cervical length in second trimester]. Chin Med Rec. 2019;20:99-102. (Chinese).

15. Jiang $\mathrm{X}$, Ying $\mathrm{H}$. [Research progress on the correlation between maternal microflora and spontaneous preterm delivery]. Chin J Obstet Gynecol. 2019;54:706-709. (Chinese).

16. Salomon LJ, Diaz-Garcia C, Bernard JP, Ville Y. Reference range for cervical length throughout pregnancy: non-parametric LMS-based model applied to a large sample. Ultrasound Obstet Gynecol. 2009;33:459-464. doi:10.1002/uog.6332

17. Chen JY, Fan XD, Chen Q, et al. [Consecutive measurement of cervical length during uncomplicated pregnancy through transvaginal ultrasound]. Chin J Perinat Med. 2012;15:16-19. (Chinese).

18. Hassan SS, Romero R, Vidyadhari D, et al.; PREGNANT Trial. Vaginal progesterone reduces the rate of preterm birth in women with a sonographic short cervix: a multicenter, randomized, double-blind, placebo-controlled trial. Ultrasound Obstet Gynecol. 2011;38:18-31. doi:10.1002/uog.9017
International Journal of General Medicine

\section{Publish your work in this journal}

The International Journal of General Medicine is an international, peer-reviewed open-access journal that focuses on general and internal medicine, pathogenesis, epidemiology, diagnosis, monitoring and treatment protocols. The journal is characterized by the rapid reporting of reviews, original research and clinical studies across all disease areas. The manuscript management system is completely online and includes a very quick and fair peer-review system, which is all easy to use. Visit http://www.dovepress.com/ testimonials.php to read real quotes from published authors. 